\title{
BACIA HIDROGRÁFICA DO RIO NATUBA - PE: UMA ANÁLISE ATRAVÉS DE PARÂMETROS MORFOMÉTRICOS
}

\author{
Cristiane Barbosa Da Silva ${ }^{(a)}$, Maria Do Socorro Bezerra De Araújo ${ }^{(b)}$, José Coelho De Araújo \\ Filho $^{(\mathrm{c})}$, Sheila Maria Bretas Bittar ${ }^{(\mathrm{d})}$ \\ (a) Departamento de Ciências Geográficas/ Universidade Federal de Pernambuco, Email: \\ cristianebarbosa2@yahoo.com.br \\ (b) Departamento de Ciências Geográficas/ Universidade Federal de Pernambuco, Email:socorro@ufpe.br \\ ${ }^{\text {(c) }}$ Embrapa Solos/ UEP - Recife, Email: coelhoembrapa@ gmail.com \\ (d) Departamento de Agronomia/Universidade Federal Rural de Pernambuco, Email: sheila.schulze@ ufrpe.br
}

\section{EIXO: BACIAS HIDROGRÁFICAS E RECURSOS HÍDRICOS: ANÁLISE, PLANEJAMENTO E GESTÃO}

\begin{abstract}
Resumo
A partir do conhecimento morfométrico de uma bacia pode-se planejar melhor os diferentes usos das terras. O objetivo do presente trabalho é a caracterização morfométrica da bacia hidrográfica do rio Natuba - PE, visando identificar atributos auxiliares para a tomada de decisão no manejo da referida bacia. Foram analisados os parâmetros morfométricos de padrão e forma de bacia hidrográfica. Os resultados apresentam os canais classificados até a quarta ordem. As densidades de drenagem e hidrográfica evidenciam a influência do forte controle estrutural e do relevo movimento. A bacia apresente histórico de cheias no período chuvoso. Porém, os dados de coeficiente de compacidade e índice de circularidade não corroboraram os dados históricos de cheias. Esta contradição pode estar associada à combinação da forma alongada da bacia e por está inserida numa zona de cisalhamento. Os parâmetros morfométricos apontam para o controle geológico - estrutural em que a bacia está inserida.
\end{abstract}

Palavras chave: diagnóstico de enchentes; hierarquia fluvial; declividade; análise de formas.

\section{Introdução}

As bacias hidrográficas constituem meios eficazes para direcionar as políticas de planejamento ambiental por apresentarem características peculiares dos aspectos naturais. Desta forma, a partir do conhecimento morfométrico das bacias podem-se planejar melhor os diferentes usos das terras.

Por ser um sistema aberto, a bacia hidrográfica apresenta uma contínua flutuação no seu estado de equilíbrio. A perda ou adição de energia permanece num delicado balanço. Por isso, a área tem influência na quantidade de água produzida como deflúvio. Por outro lado, o relevo e a forma da bacia atuam sobre a taxa de sedimentação e na quantidade de água produzida pela bacia (TONELLO et al, 2006; LIMA, 2008).

O padrão de drenagem atua na disponibilidade de sedimentos e na taxa de formação do deflúvio. Aquele é controlado ou sofre influência da estrutura geológica da bacia (TONELLO et al, 2006). A rede hidrográfica, em geral, reflete a estrutura geológica (tectônica e litológica), o clima, a evolução 
morfogenética regional e as intervenções antrópicas. Entretanto, o uso da terra é a principal atividade humana que afeta a hidrografia de uma bacia (SNADDON et. al. 1998; LATRUBESSE et al., 2005; LIMA, 2008).

A Densidade de Drenagem (Dd) possui relação direta com a pluviosidade e indireta com a estrutura geológica. Deste modo, ao analisar a Dd é necessário comparar com dados de precipitação e estrutura geológica para identificar qual é o parâmetro que sobressai no comando da Dd. Por isso, numa bacia com valor elevado de pluviosidade espera-se encontrar também um valor alto de Dd. No entanto, se a bacia hidrográfica estudada possuir rochas permeáveis, mesmo com altos índices pluviométricos, o controle geológico - estrutural sobressai favorecendo uma baixa Dd (LIMA, 2008).

De acordo com Queiroz \& Sales (2009), o coeficiente de compacidade (Kc) relaciona a forma da bacia com um círculo. Constitui a relação entre o perímetro da bacia e a circunferência de um círculo de área igual à da bacia. Seu valor está relacionado à forma, independentemente do tamanho da bacia. Considerando o círculo uma superfície regular, as bacias hidrográficas tendem a apresentar superfícies irregulares. Logo, quanto mais distanciar a forma da bacia à de um círculo, maior será o seu coeficiente de compacidade $(\mathrm{kc})$. Portanto, a susceptibilidade de uma bacia a enchentes será maior se o seu valor do Kc estiver mais próximo de 1 (valor de Kc para um círculo).

Portanto, o estudo morfométrico constitui um meio eficaz de análise das condições hidrológicas que, associado a outros elementos de sua estrutura, permitem a compreensão das dinâmicas naturais e evolução dos fenômenos decorrentes das intervenções antrópicas (QUEIROZ \& SALES, 2009). Qualquer mudança que venha ocorrer num determinado ponto da bacia, produz um ajustamento do sistema de canais-vertentes dentro desta.

A bacia hidrográfica do rio Natuba foi submetida a diversos sistemas de manejo (monocultivo, policultura e produção de hortaliças em sistema convencional e produção de hortaliças no sistema orgânico). Inicialmente foi utilizada com o cultivo de cana-de-açúcar. Nas últimas décadas foi dividida em lotes para implementação de uma agricultura familiar dedicada ao cultivo de hortaliças, raízes, frutas, entre outras, para atender uma demanda do Centro de Abastecimento e Logística de Pernambuco CEASA/PE (SILVA, 2006).

A referida bacia possui importância estratégica para o desenvolvimento econômico e sustentável da região. Do ponto de vista econômico fornece hortaliças para a Região Metropolitana do Recife - RMR, facilita a geração de trabalho e renda para pequenos produtores rurais da Zona da Mata Pernambucana. Por outro lado, o desenvolvimento sustentável foi comprometido porque a introdução das atividades agrícolas não foi precedida de estudos sistêmicos. Visando contornar esta situação diversos autores têm 


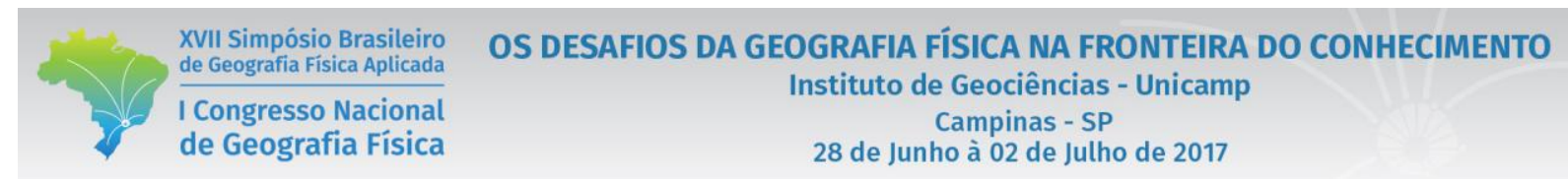

feito estudos para explicar a dinâmica natural, os processos de degradação e a produtividade da bacia (SILVA, 2006; SOUZA, 2009; BARBOSA NETO, 2011; MIRANDA, 2011; SILVA et al., 2012; ARAÚJO FILHO et al., 2013).

Desta forma, objetivo do presente trabalho é a caracterização morfométrica da bacia hidrográfica do rio Natuba, situada na Zona da Mata de Pernambuco, visando identificar atributos auxiliares para a tomada de decisão no manejo da referida bacia.

\section{Material e métodos}

A área de estudo corresponde à bacia hidrográfica do rio Natuba localizada na Zona da Mata Centro de Pernambuco, no contexto dos municípios de Vitória de Santo Antão e Pombos, com uma superfície de $38,79 \mathrm{~km}^{2}$, o que corresponde a 8,23\% da área da bacia do Tapacurá (Figura 1).

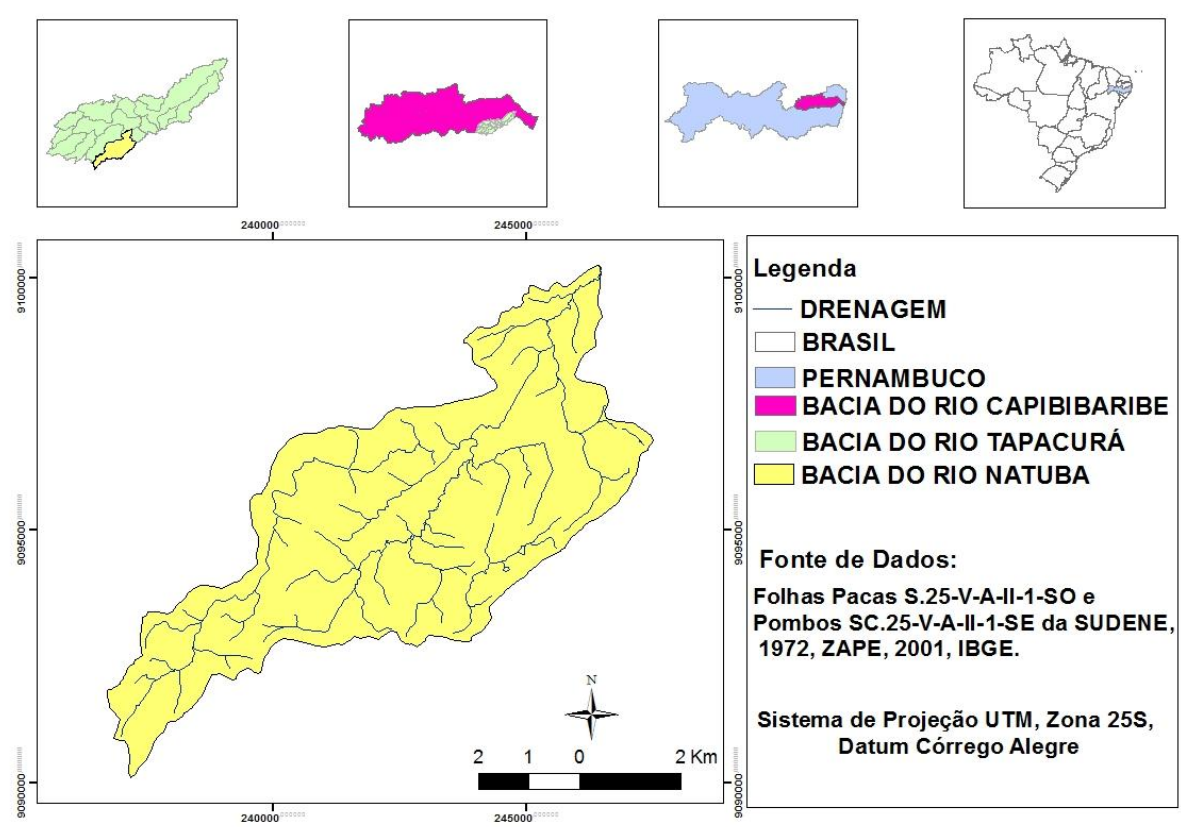

Figura 1 - Mapa de localização espacial da bacia hidrográfica do rio Natuba - PE. Fonte: Silva (2011).

A análise feita na bacia segue parâmetros morfométricos preconizados por autores como Horton (1945), Miller (1953), Schumm (1956), Strahler (1952, 1957 e 1958), Wisler \& Brater (1964), Christofoletti (1980), entre outros. 


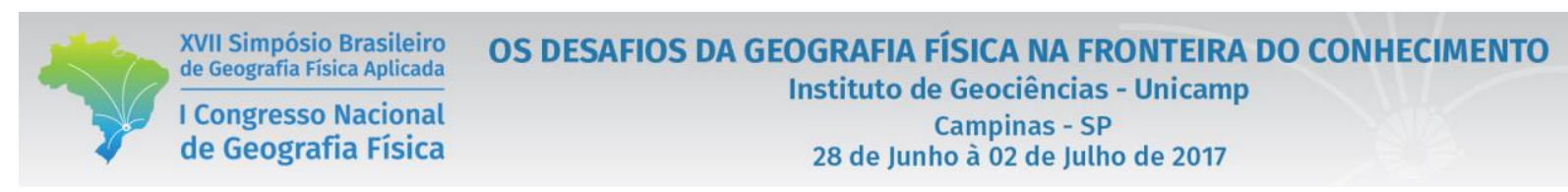

A avaliação da hierarquia fluvial foi baseada na proposta de Strahler (1957), na qual os canais sem tributários são denominados de primeira ordem e na confluência de dois canais de primeira ordem formam-se os segmentos de segunda ordem. Da confluência de dois canais de segunda ordem surgem os de terceira ordem que podem receber tributários das ordens inferiores (primeira e segunda) e assim sucessivamente.

As informações da malha de drenagem foram obtidas a partir dos mapas planialtimétricos correspondentes às folhas Pacas S.25-V-A-II-1-SO e Pombos SC.25-V-A-II-1-SE da Superintendência de Desenvolvimento do Nordeste - SUDENE (1972). As informações foram extraídas por meio da ferramenta Sketch Tools do programa ArcGIS 9.3 (do SERGEO-UFPE).

Os dados de precipitação foram obtidos junto ao Laboratório de Meteorologia de PernambucoLAMEPE (2011) e analisados para identificar o período com maiores índices pluviométricos na bacia. Estes dados forão confrontados com o resultado da Dd conforme Lima (2008).

O comprimento dos canais de drenagem foi obtido a partir da ferramenta MENSURE na barra de ferramentas tools do programa ArcGIS 9.3. Seguiu-se a proposta de Horton (1945) para determinação do comprimento médio dos canais em cada ordem, onde o valor encontrado é resultado da divisão entre o comprimento dos canais em cada ordem dividido pelo número de canais de cada ordem. O quadro I apresenta de forma sucinta os parâmetros analisados e seus respectivos significados na interpretação da área avaliada.

Quadro I - Parâmetros morfométricos analisados na bacia hidrográfica do Rio Natuba - PE

\begin{tabular}{|c|c|c|c|}
\hline \multicolumn{4}{|c|}{ PADRÃO E FORMA DA BACIA } \\
\hline Parâmetro & Fórmula & Descrição & Significado \\
\hline $\begin{array}{l}\text { Densidade de } \\
\text { Drenagem (Dd) }\end{array}$ & $\operatorname{Dd}=\frac{L t}{A}$ & $\begin{array}{l}\mathrm{Lt}=\text { comprimento } \\
\text { total dos canais. } \\
\mathrm{A}=\text { área da bacia }\end{array}$ & $\begin{array}{l}\text { Os valores elevados indicam áreas } \\
\text { de pouca infiltração e melhor } \\
\text { esculturação dos canais } \\
\text { (HORTON, 1945) }\end{array}$ \\
\hline $\begin{array}{c}\text { Densidade } \\
\text { Hidrográfica (Dh) }\end{array}$ & $\mathrm{Dh}=\frac{N t}{A}$ & $\begin{array}{l}\mathrm{Nt}=\mathrm{N}^{\circ} \text { total de } \\
\text { canais } \\
\mathrm{A}=\text { área da bacia }\end{array}$ & $\begin{array}{l}\text { Indica a capacidade em gerar novos } \\
\text { cursos de água (HORTON, 1945; } \\
\text { CHRISTOFOLETTI, 1969). }\end{array}$ \\
\hline $\begin{array}{c}\text { Coeficiente de } \\
\text { Compacidade (Kc) }\end{array}$ & $\mathrm{Kc}=0,28 \frac{P}{\sqrt{A}}$ & $\begin{array}{l}\mathbf{P}=\text { Perímetro da } \\
\text { área } \\
\mathrm{A}=\text { área da bacia }\end{array}$ & $\begin{array}{l}\text { Relaciona a bacia a uma forma } \\
\text { circular. Valores próximos da } \\
\text { unidade } 1,0 \text { a bacia tende a ser } \\
\text { circular. } \\
\end{array}$ \\
\hline $\begin{array}{c}\text { Coeficiente de } \\
\text { Manutenção }(\mathbf{C m})\end{array}$ & $\mathrm{Cm}=\frac{1}{D d} \cdot 100$ & $\begin{array}{c}\text { Dd }=\text { Densidade de } \\
\text { drenagem. }\end{array}$ & $\begin{array}{l}\text { Indica a área mínima necessária } \\
\text { para existir um metro de canal de } \\
\text { escoamento = a capacidade de } \\
\text { manter cursos perenes (SCHUMM, } \\
\text { 1956). }\end{array}$ \\
\hline $\begin{array}{c}\text { Índice de } \\
\text { Sinuosidade (Is) }\end{array}$ & & $\begin{array}{l}\mathrm{Lv}=\text { comprimento } \\
\text { verdadeiro do canal }\end{array}$ & $\begin{array}{c}\text { Indica a tendência do canal } \\
\text { principal em ser retilíneo }<1,0 \text { e/ou }\end{array}$ \\
\hline
\end{tabular}




\begin{tabular}{|c|c|c|c|}
\hline $\begin{array}{l}\text { XVII Simpósio Brasileiro } \\
\text { de Geografia Fisica Aplicada } \\
\text { I Congresso Nacional } \\
\text { de Geografia Física }\end{array}$ & \multicolumn{3}{|c|}{$\begin{array}{l}\text { OS DESAFIOS DA GEOGRAFIA FÍSICA NA FRONTEIRA DO CONHECIMENTO } \\
\text { Instituto de Geociências - Unicamp } \\
\text { Campinas - SP } \\
28 \text { de Junho à 02 de Julho de } 2017\end{array}$} \\
\hline & Is $=\frac{L v}{L r}$ & $\begin{array}{l}\text { principal. } \\
\text { Lr }=\text { comprimento } \\
\text { em linha reta do } \\
\text { canal principal }\end{array}$ & $\begin{array}{c}\text { tortuoso }>2,0, \text { transicionais } 1<>1,9 . \\
\text { Constitui o fator controlador da } \\
\text { velocidade de escoamento das } \\
\text { águas. } \\
\text { (FREITAS, 1952). }\end{array}$ \\
\hline $\begin{array}{c}\text { Extensão do } \\
\text { Percurso } \\
\text { Superficial (Eps) } \\
\end{array}$ & Eps $=\frac{1}{2 D d}$ & $\begin{array}{c}\text { Dd= Densidade de } \\
\text { drenagem. }\end{array}$ & $\begin{array}{l}\text { Representa a distância média } \\
\text { Percorrida pelas águas pluviais } \\
\text { (HORTON, 1945). }\end{array}$ \\
\hline \multicolumn{4}{|c|}{ Características do Relevo } \\
\hline Parâmetro & Fórmula & Descrição & Significado \\
\hline $\begin{array}{l}\text { Relação de Relevo } \\
\text { (Rr) }\end{array}$ & $\operatorname{Rr}=\frac{\Delta a}{L}$ & $\begin{array}{l}\Delta \mathrm{a}=\text { amplitude } \\
\text { altimétrica; } \\
\mathrm{L}=\text { comprimento do } \\
\text { canal principal }\end{array}$ & $\begin{array}{c}\text { Estabelece a relação entre a } \\
\text { diferença de altitudes máxima e } \\
\text { mínima da bacia e o comprimento } \\
\text { total do canal principal } \\
\text { (SHUMM, 1956) }\end{array}$ \\
\hline $\begin{array}{c}\text { Índice de } \\
\text { Circularidade (Ic) }\end{array}$ & Ic $=12,57 \times \mathrm{A} / \mathrm{p}^{2}$ & $\begin{array}{l}\text { Ic = Índice de } \\
\text { Circularidade } \\
\text { A = área da bacia } \\
\mathbf{P}=\text { perímetro }\end{array}$ & $\begin{array}{l}\text { Relaciona a forma da bacia a } \\
\text { forma de um círculo, quanto mais } \\
\text { próximo de } 1 \text { maior a } \\
\text { possibilidade de cheias } \\
\text { momentâneas, e diminui à medida } \\
\text { que a forma torna-se alongada } \\
\text { (TEODORO et al, 2007) }\end{array}$ \\
\hline $\begin{array}{l}\text { Fator topográfico } \\
\text { (Ft) }\end{array}$ & Ft $=$ DhxIcxRr & $\begin{array}{c}\text { Dh+= Densidade } \\
\text { hidrográfica; } \\
\text { Ic=Índice de } \\
\text { circularidade; } \\
\text { Rr+= Relação de } \\
\text { relevo } \\
\end{array}$ & $\begin{array}{l}\text { Sofre influencias dos processos de } \\
\text { inundação (MORISAWA, 1962) }\end{array}$ \\
\hline $\begin{array}{l}\text { Textura topográfica } \\
\text { (Tt) }\end{array}$ & $\begin{aligned} \log \mathrm{Tt}= & 0,219649+1,115 \\
& \operatorname{logDd}\end{aligned}$ & $\begin{array}{c}\text { Dd }=\text { Densidade de } \\
\text { drenagem }\end{array}$ & $\begin{array}{l}\text { Grau de entalhamento e } \\
\text { dissecação do relevo fornece } \\
\text { indicação do estágio erosivo da } \\
\text { região (FREITAS, 1952) } \\
\end{array}$ \\
\hline $\begin{array}{l}\text { Gradiente dos } \\
\text { canais }(\mathrm{Gc})(\%)\end{array}$ & $\mathrm{Gc}=\frac{\text { Alt.max }}{L}$ & $\begin{array}{l}\text { Alt. Max }=\text { Altitude } \\
\text { máxima } \\
\text { L= comprimento do } \\
\text { canal principal }\end{array}$ & $\begin{array}{l}\text { Indica a declividade dos cursos } \\
\text { d'água (FREITAS, 1952) }\end{array}$ \\
\hline $\begin{array}{c}\text { Índice de } \\
\text { Rugosidade (Ir) }\end{array}$ & Ir $=\mathbf{H m} \times$ Dd & $\begin{array}{c}\text { Hm= amplitude } \\
\text { altimétrica máxima da } \\
\text { bacia; } \\
\text { Dd= Densidade de } \\
\text { drenagem }\end{array}$ & $\begin{array}{l}\text { Mostra a relação declividade com } \\
\text { os comprimentos dos canais, } \\
\text { quanto maior for o índice implica } \\
\text { em relevo mais colinoso e } \\
\text { dissecado (maiores declividades) } \\
\text { canais mais entalhados } \\
\text { (STRAHLER, 1958). } \\
\end{array}$ \\
\hline
\end{tabular}

Fonte: Silva (2011).

\section{Resultado e Discussões}

Na hierarquia fluvial obteve-se um total de 75 canais somando um comprimento de 80,90 km de extensão (Tabela I). Desses 75 canais, 54 são de primeira ordem, 15 de segunda ordem, 5 de terceira 
ordem e 1 de quarta ordem. A relação número de canais por área da bacia ilustra que para cada km² existe 1,93 canais. Destes, 93,33\% possuem menos de 1km de extensão. Este resultado está em consonância com a interpretação de Christofoletti (1980) sobre hierarquia fluvial. Onde para o referido autor quanto maior o número de canais por área menor será o comprimento destes canais. Os canais mais expressivos são, em termos de extensão individual de canal, os de terceira e quarta ordem que correspondem a $6,67 \%$ de todos os canais (Figura 2).

Tabela I - Dados Lineares da malha de drenagem na bacia do Rio Natuba - PE

\begin{tabular}{c|c|c|c}
\hline Ordem & $\mathrm{N}^{\mathbf{o}}$ de Seguimentos & $\begin{array}{c}\text { Comprimento Total dos } \\
\text { canais km }\end{array}$ & $\begin{array}{c}\text { Comprimento Médio } \\
\text { dos canais -Lm km }\end{array}$ \\
\hline $1^{\mathrm{a}}$ & 55 & 43,44 & 0,80 \\
\hline $2^{\mathrm{a}}$ & 15 & 14,35 & 0,96 \\
\hline $3^{\mathrm{a}}$ & 5 & 14,90 & 2,98 \\
\hline $4^{\mathrm{a}}$ & 1 & 8,21 & $-\cdots, 21$ \\
\hline Total & 75 & 80,90 & - \\
\hline \multicolumn{2}{|c}{ Fonte: Silva (2011). }
\end{tabular}

Como indicativo de uma boa compreensão do ambiente, o índice de área (Tabela III), associado a outros parâmetros possibilita um manejo mais adequado dos recursos naturais (QUEIROZ \& SALES, 2009) identificando a capacidade de suporte destes às atividades desenvolvidas na região. A bacia hidrográfica do rio Natuba apresenta uma área de $38,79 \mathrm{~km}^{2}$ e um perímetro de $38,21 \mathrm{~km}$. O comprimento verdadeiro do rio (projeção ortogonal) principal é de 17,40 km, já a distância vetorial (o comprimento em linha reta entre a nascente e a foz) é de 13,30 km. 

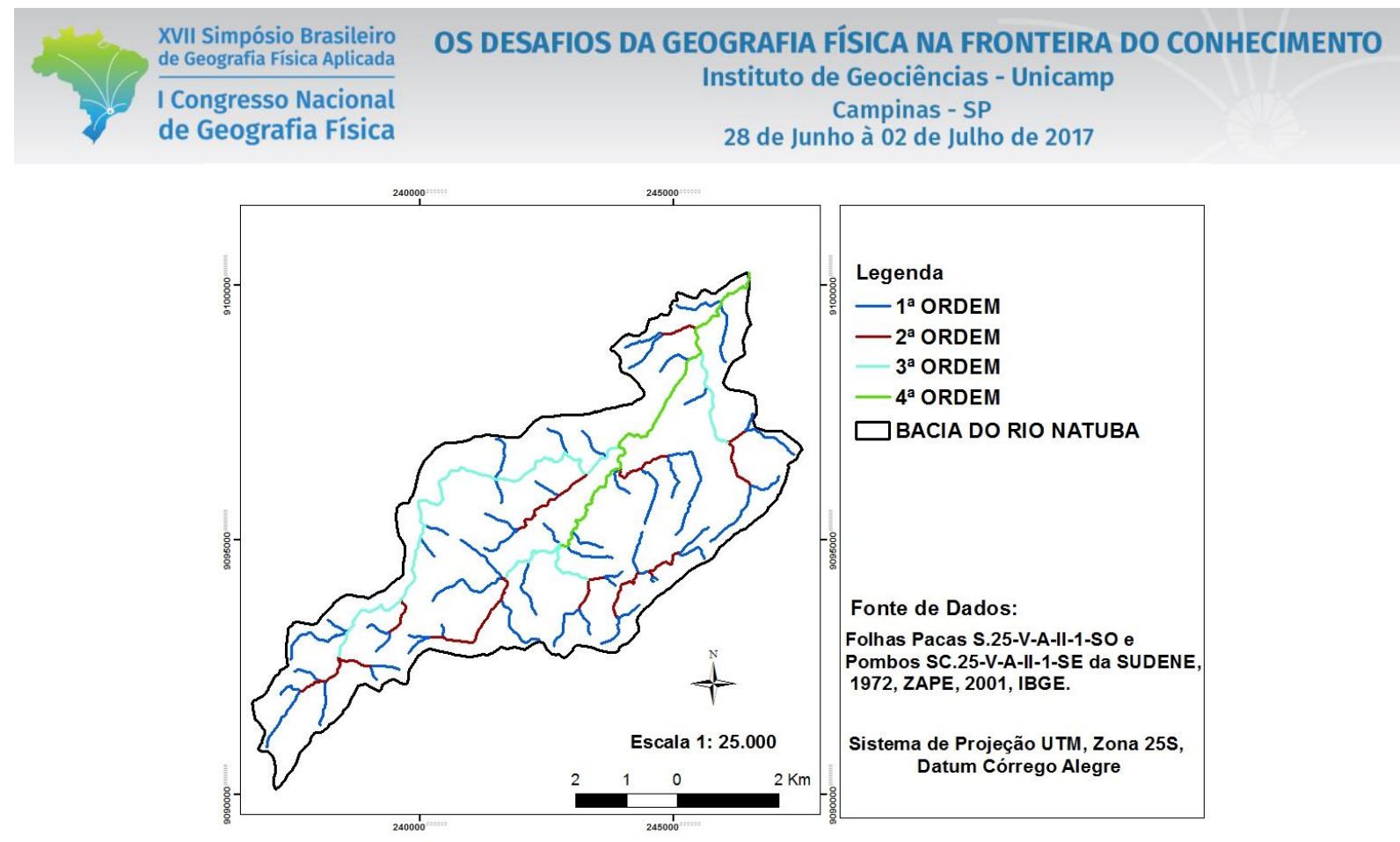

Figura 2 - Mapa da Hierarquia Fluvial da bacia hidrográfica do rio Natuba - PE. Fonte: Silva (2011).

O Coeficiente de Manutenção é de 1,24 m²/m, sendo esta área mínima para manutenção de um metro de canal de escoamento da bacia. A Extensão do Percurso Superficial é de 0,17 (Tabela II). Este valor demonstra que as águas das chuvas percorrem em média até $17 \mathrm{~m}$ do interflúvio até o leito do rio mais próximo. Quanto maior for o resultado deste parâmetro, mais predisposta à erosão a bacia poderá está no momento, sendo assim um indicativo de ajustamento às condições naturais. Associando estes parâmetros morfométricos com os dados de declividade da bacia $\left(9,51 \mathrm{~km}^{2} \mathrm{com}\right.$ declividade inferior a $3 \%$; $11,44 \mathrm{~km}^{2}$ entre $3 \%$ e $8 \% ; 9,75 \mathrm{~km}^{2}$ entre $8 \%$ e $20 \% ; 6,37 \mathrm{~km}^{2}$ entre $20 \%$ e $45 \%$ e $1,72 \mathrm{~km}^{2}$ com declividade acima de $45 \%$ ) observa-se que existe uma alta suscetibilidade aos processos erosivos. Adicionalmente, os resultados do Coeficiente de Manutenção e da Extensão do Percurso Superficial corroboram com parâmetros físicos (densidade e porosidade) analisados por Silva (2011) e os dados de solos levantados por Araújo Filho et al. (2013).

Tabela II - Dados areais da bacia hidrográfica do Rio Natuba - PE

\begin{tabular}{c|c}
\hline Parâmetros & Resultados \\
\hline Área $\left(\mathrm{Km}^{2}\right)$ & $38,79 \mathrm{~km}^{2}$ \\
\hline Perímetro $(\mathrm{Km})$ & $38,21 \mathrm{Km}$ \\
\hline Comprimento verdadeiro $(\mathrm{km})$ & $17,40 \mathrm{Km}$ \\
\hline Comprimento vetorial $(\mathrm{km})$ & $13,30 \mathrm{Km}$ \\
\hline Extensão do percurso superficial $(\mathrm{m})$ & $0,17 \mathrm{~m}$ \\
\hline Coeficiente de manutenção $\left(\mathrm{m}^{2} / \mathrm{m}\right)$ & $1,24 \mathrm{~m}^{2} / \mathrm{m}$ \\
\hline Densidade de drenagem $\left(\mathrm{km} / \mathrm{km}^{2}\right)$ & $2,96 \mathrm{Km} / \mathrm{Km}^{2}$ \\
\hline Densidade Hidrográfica $\left(\mathrm{rios} / \mathrm{km}^{2}\right)$ & $1,93 \mathrm{rios} / \mathrm{Km}^{2}$ \\
\hline
\end{tabular}


Fonte: Silva (2011).

Na região da bacia ocorre alta pluviosidade, com média situada na faixa de $1.008 \mathrm{~mm}$ e $1.395 \mathrm{~mm}$, com $70 \%$ das chuvas concentradas no período de março a junho, segundo dados do LAMEPE (2011). A Dd 2,96 km/ $\mathrm{km}^{2}$ indica que a bacia hidrográfica do rio Natuba, seguindo os critérios estabelecidos por Christofoletti (1969), possui baixa densidade de drenagem.

Ao confrontar os dados de pluviosidade e Dd percebe-se que a explicação mais plausível está relacioanda ao forte controle geológico - estrutural (com rochas bastante fraturadas) associado a um relevo plano $(24,54 \%)$, suave ondulado $(29,48 \%)$, ondulado $(25,14 \%)$, forte ondulado $(16,41 \%)$ e montanhoso $(4,43 \%)$ e a presença de solos profundos propiciando uma maior infiltração em detrimento do escoamento superficial, conforme Silva (2011).

A densidade hidrográfica foi 1,93 canais $/ \mathrm{km}^{2}$ (Tabela II). Quando o valor da densidade de drenagem (Dd) é superior ao valor da densidade hidrográfica (Dh), reflete um acentuado controle estrutural, alongando o comprimento dos canais, o que reflete num menor número de canais (QUEIROZ \& SALES, 2009). Logo, a bacia hidrográfica do rio Natuba apresenta forte controle estrutural, fato este justificado por encontra-se em uma zona de falhas expressivas que é o Lineamento Pernambuco. O Coeficiente de Compacidade $(\mathrm{Kc})$ para a área estudada é 1,75. Este resultado demonstra que a bacia hidrográfica do rio Natuba apresenta pouca possibilidade de cheias uma vez que seu coeficiente se distancia de 1.

Assim como o Kc, o Índice de circularidade (Ic) relaciona a forma da bacia a de um círculo. $\mathrm{O}$ resultado encontrado para este parâmetro foi de 0,33 e, de acordo com Teodoro et al (2007), o valor quando se distancia de 1 demonstra que a área analisada possui forma alongada (com pode ser visto na Figura 3) e apresenta pouca possibilidade de cheias momentâneas.

Esses resultados, de Kc e Ic, podem confundir os planejadores de políticas públicas. Deve-se ter em mente que, em áreas que apresentem controle estrutural forte, representado pela apresentação de canais retilíneos, a velocidade de escoamento do canal pode causar cheias momentâneas. Por isso, na bacia hidrográfica do rio Natuba, no baixo curso poderá ocorrer cheias momentâneas devido à presença de canais retilíneos e a presença da zona de cisalhamento. Foi verificado histórico de cheias na comunidade do assentamento Natuba, próximo a BR 232. Estas cheias foram relatadas pelos agricultores e discutidas pela mídia local (Figura 4). 
Campinas - SP

28 de Junho à 02 de Julho de 2017

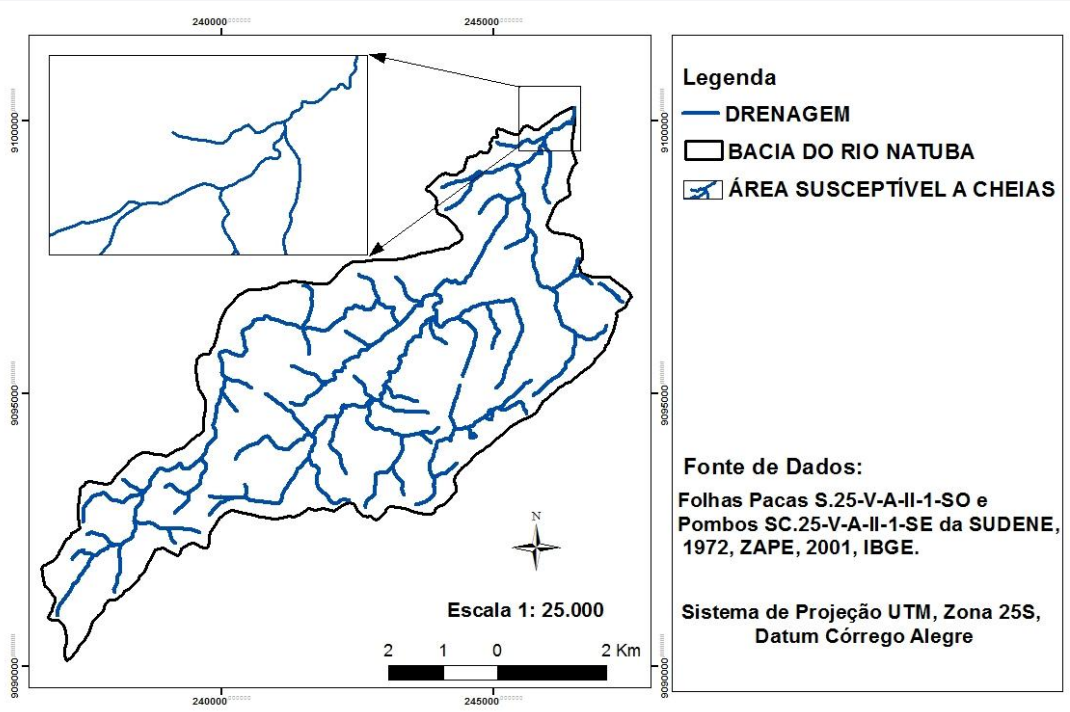

Figura 3 - Mapa da área com maior susceptibilidade a cheias da bacia hidrográfica do rio Natuba - PE. Fonte: Silva (2011).

Para a bacia analisada o índice de sinuosidade (Is) foi de 1,30. Este valor demonstra que o canal da bacia tende a ser transicional (varia entre 1 e 1,9). A sinuosidade dos canais da bacia sofre um forte controle geológico - estrutural (Tabela III).

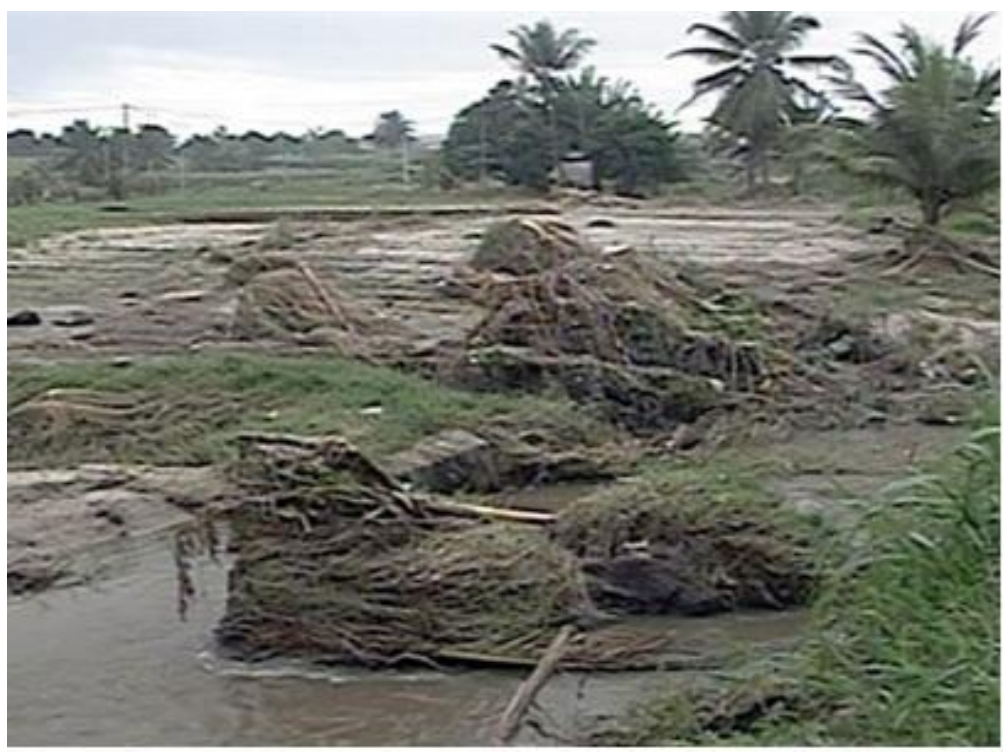

Figura 4 - Cheia no baixo curso do rio Natuba - PE (próximo a BR 232). Fonte: Nascimento no blog a Voz de Vitória (2009).

Tabela III - Dados topográficos da bacia hidrográfica do Rio Natuba. 


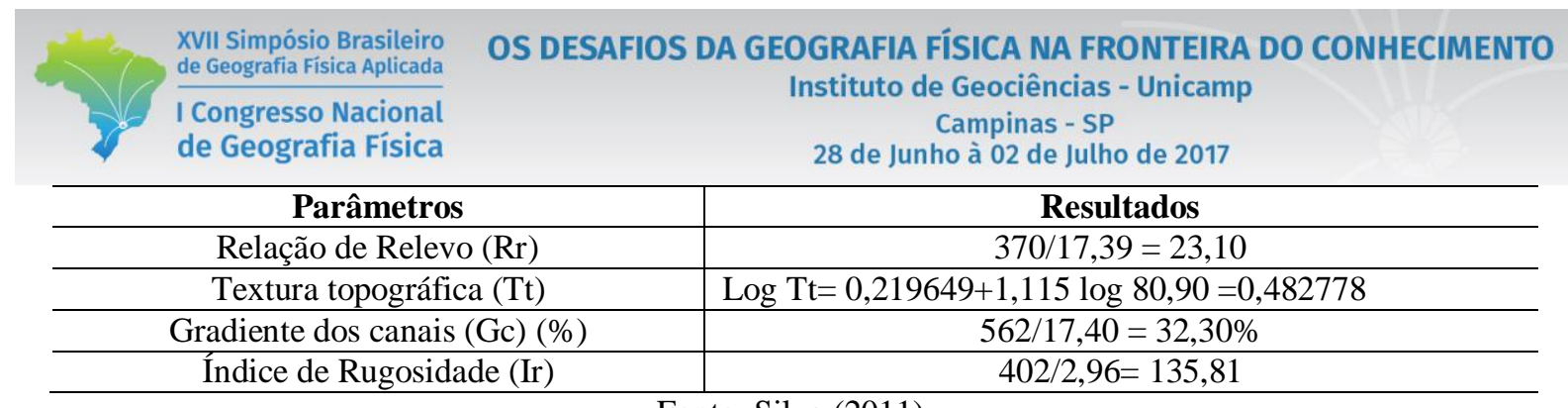

Fonte: Silva (2011).

O índice de rugosidade encontrado foi de 135,81 este valor indica uma área com topografia colinosa, dissecada e com canais mais entalhados. Estes dados são semelhantes aos encontrados por Castro \& Carvalho (2009) estudando a bacia hidrográfica do rio Turvo (GO). Embora, os estudos tenham sido feitos em domínios morfoclimáticos distintos ambos estão em superfícies tropicais estabilizadas.

Adicionalmente na análise do gradiente dos canais de drenagem foi encontrado o valor de $32,30 \%$ de declividade do curso principal, entre a nascente e a foz, mais uma evidencia de relevo movimento que favorece o escoamento superficial. Outra característica que corrobora para este escoamento superficial é a forte coesão dos solos indicada no trabalho de Araújo Filho et al. (2013).

\section{Conclusões}

Os parâmetros morfométricos apontam para o controle geológico - estrutural em que a bacia está inserida.A bacia possui baixa densidade de drenagem por estar em uma área bastante movimentada, com clima tropical que favorece o intemperismo e o desenvolvimento de solos profundos. Sendo que os principais motivos das cheias estão associados à presença de canais retilíneos, as formas do relevo e a coesão dos solos.

Os índices Kc e Ic não explicaram, por si só, a dinâmica de cheias da bacia. Por isso, como estudos futuros, sugere-se aplicar estes mesmos índices no maior número de bacias hidrográficas que já possuam histórico de cheias para corroborar ou negar o resultado encontrado nesta pesquisa.

\section{Agradecimentos}

Ao Conselho Nacional de Desenvolvimento Científico e Tecnológico - CNPq pela bolsa de mestrado concedida à primeira autora do trabalho.

Ao Laboratório de Geoprocessamento e Sensoriamento Remoto -UFPE por permitir o uso do software ArcGIS 9.3 para realização da análise morfométrica deste trabalho.

\section{Bibliografia}


ARAÚJO FILHO, J. C.; BARBOSA NETO, M. V.; SILVA, C. B.; ARAÚJO, M. S. B.; MENEZES, J. B. Levantamento Semidetalhado dos Solos da Bacia Hidrográfica do Rio Natuba, Pernambuco. In: Revista Brasileira de Geografia Física, Recife, v. 6, n. 3, p.384-397, 2013.

BARBOSA NETO, M. V. Zoneamento da aptidão agrícola e uso dos solos da área do médio curso do rio Natuba - PE. 2011. 135 f. Dissertação (Mestrado em Geografia) - Programa de Pós-Graduação em Geografia, Universidade Federal de Pernambuco, Recife.

CASTRO, S. B.; CARVALHO, T. M. Análise morfométrica e geomorfologia da bacia hidrográfica do rio Turvo GO, através de técnicas de Sensoriamento Remoto e Geoprocessamento. In.: Revista Scientia Plena, Aracaju, v. 5, n. 2, p. 1- 7, fev.2009.

CHRISTOFOLETTI, A. Análise morfométrica das bacias hidrográficas. Notícia Geomorfológica, Campinas, v. 9 , n. 18 , p. 36-64, 1969.

Geomorfologia. $2^{a}$ ed. São Paulo: Edgar Blücher, 1980, 188p.

FREITAS, R. O. Textura de drenagem e sua aplicação geomorfológica. Boletim Paulista de Geografia. São Paulo, n. 11, p. 53-57, 1952.

HORTON, R. E. Erosional development of streams and their drainage basins: Hidrophysical approach to quantitative morphology. Geological Society of America Bulletin, Colorado v. 56, n3, p275-370, mar. 1945.

LAMEPE - Laboratório de Meteorologia de Pernambuco. Dados de Precipitação dos municípios de Pombos e Vitória de Santo Antão: Série histórica. Disponível em: http: www.itep.br/LAMEPE.asp Acessado em 20 jan./2011.

LATRUBESSE, E. M.; STEVAUX, J. C.; SINHA, R. Tropical Rivers. In.: Geomorphology. Amsterdam, v. 70, n. 3-4, p. p.187 - 206, 2005.

LIMA, W. P. Princípios de hidrologia florestal para o manejo de bacias hidrográficas. $2^{\text {a }}$ ed. Piracicaba: ESALQ, 2008, 253p.

MIRANDA, E. C. SUSTENTABILIDADE DE ÁREAS COM HORTICULTURA NO SISTEMA ORGÂNICO E NO CONVENCIONAL E SEU IMPACTO NAS CONDIÇÕES SOCIO - ECONÔMICAS DA COMUNIDADE DE ASSENTADOS NA BACIA DO RIO NATUBA - PE. 2011. 98 f. Dissertação (Mestrado em Geografia) - Programa de Pós-Graduação em Geografia, Universidade Federal de Pernambuco, Recife.

MILLER, V. C. A Quantitative Geomorphic Study of Drainage basin characteristic in the Clinch Mountain Area. Virginia and Tennessee. Dept. of Geology Columbia University, New York, n.3, p. 389 - 402, set. 1953.

MORISAWA, M. E. Quantitative geomorphology of some watersheds in the Appalachian Plateau. Geological Society of America Bulletin. Colorado, v. 73, n. 9 p. 1025-1046, set.1962.

QUEIROZ, P. B.; SALES, M.C.L. Caracterização Geoambiental e Morfométrica de um trecho do médio curso da bacia hidrográfica do rio Pacoti. In.: XIII Simpósio Brasileiro de Geografia Física Aplicada, 2009, Viçosa. Anais do XIII Simpósio Brasileiro de Geografia Física Aplicada. Viçosa: Universidade Federal de Viçosa, 2009.

SCHUMM, S. A. Evolution of drainage systems and slopes in badlands of Perth Amboy. Geological Society of America Bulletin. Colorado, v. 67, n.5, p. 597-646, mai. 1956.

SILVA, C. E. M. USO E OCUPAÇÃO DO SOLO EM ÁREAS DE PRESERVAÇÃO PERMANENTES DA BACIA HIDROGRÁFICA DO NATUBA, AFLUENTE DO TAPACURÁ - PE. 2006. 65 f. Monografia (Graduação em Ciências Biológicas) - Centro de Ciências Biológicas, Universidade Federal de Pernambuco, Recife.

SILVA, C. B. Delimitação das Unidades Geoambientais da Bacia do rio Natuba e estimativa de estoque de carbon no Médio Natuba, Zona da Mata Centro/PE. 2011. 181 f. Dissertação (Mestrado em Geografia) Programa de Pós-Graduação em Geografia, Universidade Federal de Pernambuco, Recife.

SILVA, C. B.; ARAÚJO, M. S. B.; ARAÚJO FILHO, J. C.; SCHUlZE, S. M. B. B. Delimitação de Geoamabientes numa Bacia Hidrográfica na Zona da Mata de Pernambuco. In: Revista Brasileira de Geografia Física, Recife, v. 5, n. 5, p. 1259-1274, 2012. 
SOUZA, S. F. AVALIAÇÃO DA SUSCEPTIBILIDADE À EROSÃO DOS SOLOS DA SUB-BACIA DO ALTO NATUBA - PE: AGREGAÇÃO E COBERTURA VEGETAL. 2009. 85 f. Dissertação (Mestrado em Geografia) - Programa de Pós-Graduação em Geografia, Universidade Federal de Pernambuco, Recife.

SNADDON, C. D.; WISHART, M. J.; DAVIES, B. R. Some implications of inter-basin water transfer for river ecosystem functioning and water resources management in Southern Africa. In.: Aquatic Ecosystem Health and Management, Philadelphia, v. 1. N. 2, p. 159-182, nov.1998.

STRAHLER, A.N. Hypsometric (area-altitude) analysis and erosional topography. Geological Society of America Bulletin, Colorado, v. 63, n.11, p. 1117-1142, nov.1952.

571-596, mai. 1956 Quantitative slope analysis. Geological Society of America Bulletin, Colorado, v. 67, n.5, p. Quantitative Analysis of Watershed Geomorphology. In.: Transactions, American Geophysical Union, Washington, v. 38 n. 6, p.913-920, dez.1957.

. Dimensional analysis applied to fluvial eroded landforms. Geological Society of America Bulletin, Colorado, v. 69, n.3, p.279-300, mar. 1958.

SUDENE - Superintendência de Desenvolvimento do Nordeste: Biblioteca Celso Furtado, cartas topográficas folhas Pacas SC.25-V-A-II-1SE e Vitória de Santo Antão SC.25-V-A-II-1-NE 1:25.000, Recife: SUDENE, 1972.

TEODORO, V. L. I.; TEIXEIRA, D.; COSTA, D. J. L.; FULLER, B. B. O conceito de bacia hidrográfica e a importância da caracterização morfométrica para o entendimento da dinâmica ambiental local. In.: Revista UNIARA, Araraquara, v.11, n. 1, p135-157, jan./jun.2007.

TONELLO, K. C.; DIAS, H. C. T.; SOUZA, A. L. RIBEIRO, C. A. A. S.; LEITE, F. P. Morfometria da bacia hidrográfica da Cachoeira das Pombas, Guanhães - MG. In.: Revista Árvore, Viçosa, v. 30, n.5, p.849 - 857, set./out. 2006. 